\title{
ARTICLE OPEN \\ Kinetics of pipeline steel corrosion studied by Raman spectroscopy-coupled vertical scanning interferometry
}

\author{
Janis Heuer ${ }^{1}$ and Andreas Luttge $\mathrm{e}^{1,2,3}$
}

The corrosion and degradation of materials, such as pipeline steel, have a strong effect on both the environment and the economy. The quantification of these processes can therefore provide important information needed to manage their impact. In this study, a concept for the characterization and quantification of corrosion is demonstrated on API X70 steel immersed in $3.5 \mathrm{wt} . \% \mathrm{NaCl}$ solution. Due to the difficulty of quantifying corrosion rates, e.g., through single mean values, a unique system is applied that directly couples Raman spectroscopy with vertical scanning interferometry to assess the physical and chemical aspects of steel corrosion kinetics. Vertical scanning interferometry allows the quantification of the topographical evolution of corrosion product formation and material dissolution in combination with the direct measurements of the respective rates. The Raman spectroscopy provides additional information about the (mineral) phases. Rate variations ranging from uniform corrosion to areas of high pit densities are quantified and analyzed in rate maps and subsequently visualized in rate spectra. The rate distribution is classified into different domains and pitting rates. Thus, a comprehensive quantitative assessment of the characteristic corrosion behavior is discussed.

npj Materials Degradation (2018)2:40; https://doi.org/10.1038/s41529-018-0061-2

\section{INTRODUCTION}

Modern industrial societies must invest a significant amount of the national gross product to maintain their infrastructure and fight its corrosion. The lifetime and velocity of degradation of solid material is a major concern to engineers, researchers, managers, and politicians. The corrosion of pipelines is a particularly important economical factor for the oil and gas industry where costs can easily exceed billions of dollars each year. ${ }^{1}$ Furthermore, material failure can result in pipeline leakages with substantial environmental impact. These facts are strong arguments for intense research efforts that have led to a wealth of information and knowledge about corrosion. ${ }^{2-9}$

In the field of geochemistry, Luttge and co-workers ${ }^{10-12}$ have demonstrated that mineral dissolution rates may vary significantly. This variation depends on specific characteristics related to intrinsic properties of solid materials, such as crystal lattice defects. $^{10,11}$ In many cases, this work created some serious doubt about the validity of using simple mean values, i.e., rate constants. Alternatively, the reaction behavior of a dissolving mineral surface can be quantified by measuring topography changes. ${ }^{10}$ The surface normal retreat is obtained by measuring the local height development in a series of time frames and subtracting these from each other, hereby generating a material flux map. ${ }^{12}$ These surface normal retreat values are then converted into reaction rates that can be visualized in a rate map. Finally, the rate distribution is analyzed in a histogram, termed a rate spectrum. ${ }^{12}$ Through deconvolution of the rate spectra different rate contributing modes are revealed, providing a statistical approach to reaction rates and serving as a basis for mechanistic interpretion. ${ }^{10}$

In the case of steel, metal "dissolution" occurs as part of the corrosion process. Many different rate contributing factors have to be taken into consideration, as different compositional and microstructural properties can lead to significant corrosion rate variations (e.g., $0.8 \mathrm{~mm}$ year $^{-1}$ to $3.2 \mathrm{~mm}$ year $^{-1}$ ). ${ }^{13}$ Particularly pitting corrosion shows accelerated dissolution ${ }^{5}$ due to chemical or physical heterogeneities ${ }^{2}$ (Fig. 1).

Previous studies have utilized interferometry to assess corrosion behavior. ${ }^{14-16}$ These studies show the powerful capabilities of characterizing pitting corrosion, e.g., pit density and pit geometry ${ }^{14,16}$ as well as uniform corrosion. ${ }^{15}$ In this study, the characterization of uniform and localized corrosion is demonstrated, by quantifying the relationship between the corrosion products on the surface and the steel dissolution underneath. Methods of previous studies such as the measurements of surface topography after cleaning off the corrosion products are incorporated. ${ }^{15}$ This allows the generation of rate and corrosion product maps that are further quantified via the rate spectra concept. $^{10-12}$

The corrosion kinetics are studied with a new surface sensitive measuring method, Raman spectroscopy-coupled vertical scanning interferometry (RC-VSI). This setup has the capacity of linking precise centimeter to nanometer scale surface topographic measurements with the mineral or material phases and alterations that occur at the reacting surface. This information adds significantly to a wide range of possibilities that allow a comprehensive quantitative description of corrosion behavior.

The RC-VSI system enables direct overlay of Raman spectroscopy maps and surface topography maps. Subsequently, rate maps are produced by subtracting consecutive topography maps. Finally, through data processing, rate maps are directly correlated with Raman spectroscopy maps. This procedure generates a direct correlation between surface reaction rates and composition. This

\footnotetext{
${ }^{1}$ Fachbereich Geowissenschaften, University of Bremen, 28359 Bremen, Germany; ${ }^{2}$ MARUM, University of Bremen, 28359 Bremen, Germany and ${ }^{3}$ MAPEX, University of Bremen, 28359 Bremen, Germany

Correspondence: Andreas Luttge (aluttge@uni-bremen.de)
}

Received: 20 June 2018 Accepted: 20 November 2018

Published online: 10 December 2018 


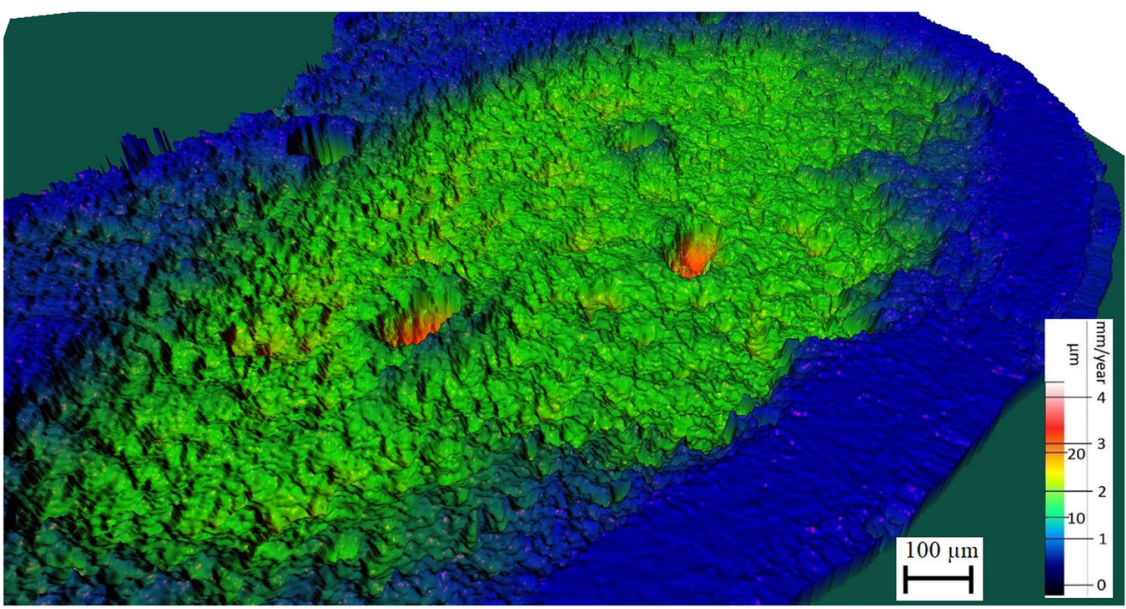

Fig. 13 D topography image of corroded steel surface: A 3D view of sample B's topography after the corrosion products have been cleaned off (after $72 \mathrm{~h}$ immersion). The colors as described in the legend show the surface normal retreat $(\mu \mathrm{m})$ and corrosion rate $\left(\mathrm{mm}^{-1}\right.$ year $\left.{ }^{-1}\right)$. Deep pits (red color) are dispersed throughout the surface. A rather uniform corroded area is located in the center region of the sample (green color). This region is surrounded by an area of very low corrosion forming the boundary of the sample (blue color)

work demonstrates a concept that can give insight into steel corrosion kinetics and provide quantification of corrosion rates via topography measurements with up to nanometer scale vertical resolution.

Below, the utilization of the previously outlined method is tested on API X70 pipeline steel undergoing corrosion in an $\mathrm{NaCl}$ solution.

\section{RESULTS}

\section{Topography observations}

The initially polished surface was measured by vertical scanning interferometry (VSI). Minor scratches ranging from 1 to $3 \mu \mathrm{m}$ in depth are observed (Fig. 2, A1-C1). The quantification of surface roughness was done by using two roughness parameters, i.e., the roughness average $\left(R_{\mathrm{a}}\right)$, which is the average mean height, and the root mean square $\left(R_{\mathrm{q}}\right)$, which describes the standard deviation from the mean height. All three samples initially show very low roughness values due to the polishing procedure, i.e., $R_{\mathrm{a}}=63 \mathrm{~nm}$ and $R_{\mathrm{q}}=87 \mathrm{~nm}$ (Table 1 ).

Conducting the corrosion experiment, after a time interval of $5 \mathrm{~h}$ in $3.5 \mathrm{wt} . \% \mathrm{NaCl}$ solution, the topography data show that more than half of the initial surface is covered with a layer of corrosion products. These products have a grain-like texture (Fig. 2, A2-C2). The border between the corrosion products and the bare steel surface is visible (Fig. 2, A2-C2). As explained in the method section (Fig. 6 (2)) all height data reported are initially apparent height values because they are measured using the embedding material as a reference. Only after the corrosion products have been removed with Clarke's solution the absolute corrosion product height and volume can be determined. The same applies for the quantification of surface-normal retreat rates.

After $5 \mathrm{~h}$ the apparent height of the corrosion products averages at around $10 \mu \mathrm{m}$, with a maximum of $25 \mu \mathrm{m}$. The border between the corrosion products and the steel surface has a curved shape, seen in sample C (Fig. 2, C2). Different morphologies of the corrosion products are observed: In sample $A$ the corrosion products have formed an oval shape in the upper middle center (Fig. 2, A2), while products in sample B show smaller circular shapes with height values of $25 \mu \mathrm{m}$ that are distributed across the surface (Fig. 2, B2).

The roughness analyses (Table 1) provide further quantification of the surface alteration. After $5 \mathrm{~h}$ of immersion the surface roughness values increase significantly to $R_{\mathrm{a}}=6354 \mathrm{~nm}$ and $R_{\mathrm{q}}=$ $7828 \mathrm{~nm}$ due to the formation of the corrosion products.
After $72 \mathrm{~h}$ of immersion in the $\mathrm{NaCl}$ solution (Fig. 2, A3-C3), the corrosion products reside on the outer perimeters of the samples reaching heights of over $100 \mu \mathrm{m}$. Whereas in the center substantial lower height values and even negative height values are measured revealing the dissolution of the steel surface. Sample C (Fig. 2, C3) exhibits a different pattern as the height values are distributed rather homogenously across the surface reaching up to $140 \mu \mathrm{m}$ and only two smaller areas of low and negative height values are present. The corrosion products formed after $72 \mathrm{~h}$ of immersion cause an increase in surface roughness values that are over 400 times higher than the initial polished surface's roughness, with values of $R_{\mathrm{q}}=24,697 \mathrm{~nm}$ and $R_{\mathrm{a}}=$ 29,210 nm (Table 1).

The circular formations observed after the first $5 \mathrm{~h}$ (Fig. 2, A2 -C2) disappear largely after $72 \mathrm{~h}$. Instead, pit areas with negative height values are now revealed (Fig. 2, A3-C3). The Raman spectrometer coupled with the VSI instrument is then used to analyze the corrosion products. As an example Fig. 2, B3 shows an area of a Raman measurement located at pit on the surface of sample B (Fig. 2, B3). These pits become even more pronounced after cleaning off all corrosion products (Fig. 2, A4-B4) and are documented in more detail in the rate maps section.

Raman spectroscopy-coupled vertical scanning interferometrymeasurements (R-VSI)

Before cleaning off the corrosion products, Raman measurements (Fig. 3) of the area indicated in Fig. 2 (B3) were performed. A light optical microscope image (Fig. 3, (2)) shows the different coloring of corrosion products surrounding the pit ranging from red, orange to black. The corresponding Raman map shows the intensity of the $670 \mathrm{~cm}^{-1}$ vibrational band.

Strong Raman bands at 253,380,529,658, and $1305 \mathrm{~cm}^{-1}$ are found surrounding the right side of the pit (Fig. 3, (3)) and are identified as lepidocrocite (see Methods for description of identification). Whereas a strong vibrational band at $673 \mathrm{~cm}^{-1}$ and small bands at 244,314, and $543 \mathrm{~cm}^{-1}$, that correspond to magnetite, are located mainly in middle of the pit (Fig. 3, (4)). The rest of the area was identified as a mixture of Fe-hydroxides and oxides. The topography (Fig. 3, (5)) resembles the shape found in the Raman map as well as in the light microscope image. In close vicinity to the deep pit center an oval heightened hill gives the pit its characteristic shape. The majority of the pit is covered by corrosion products, only after cleaning them off two small pits are revealed (Fig. 3, (6)). Converting the surface normal retreat data 

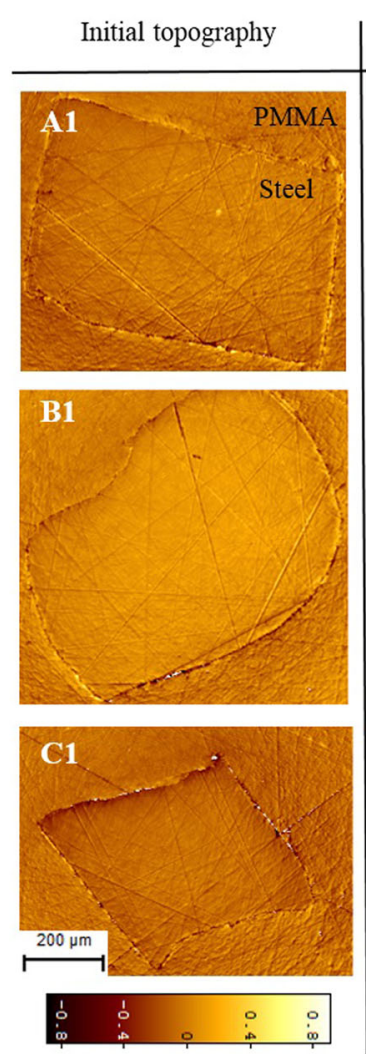
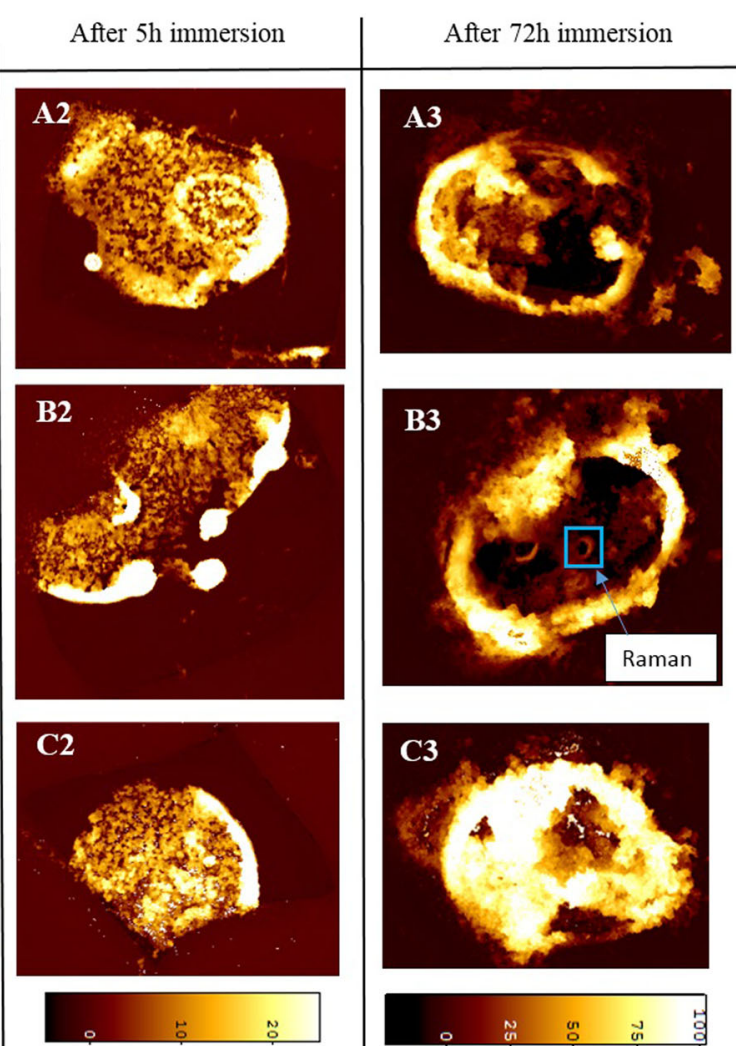
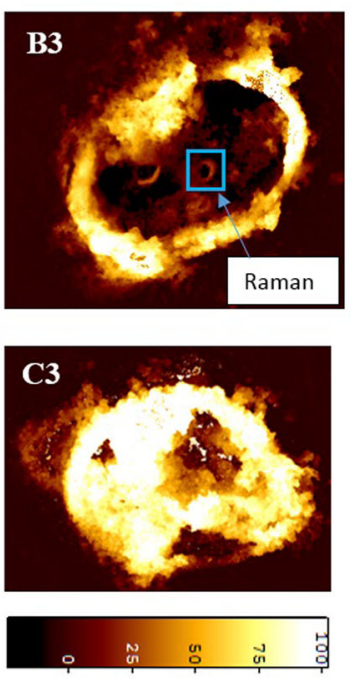

height $[\mu \mathrm{m}]$
After Clarke's solution
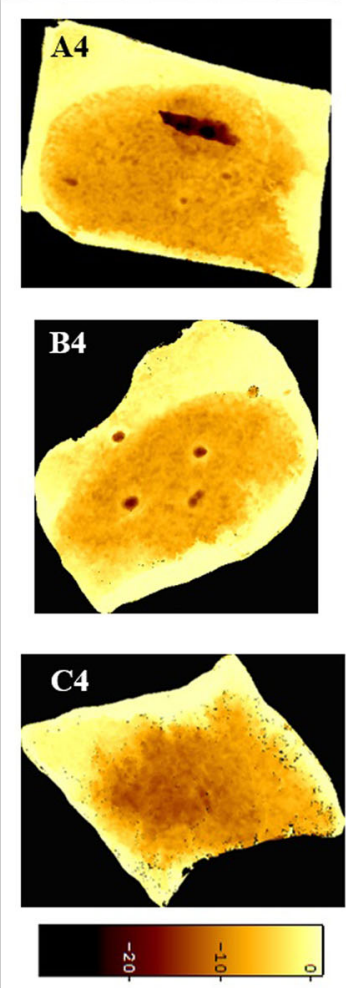

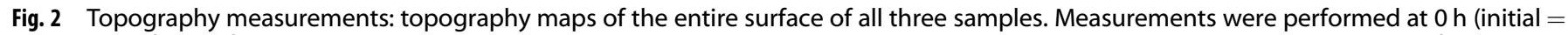
polished surface), after 5 and $72 \mathrm{~h}$ immersion (in $3.5 \mathrm{wt} \% \mathrm{NaCl}$ ). The height scale bar is located below. A1-C1 The polished surface still has minor scratches of $1-3 \mu \mathrm{m}$. Note that the height scale bars vary as the height values increase with immersion time. Therefore, the original sample shape is barely visible on (A2-C2) and (A3-C3), due to their low height. A2-C2 After 5 h the corrosion products have already covered the majority of the surface with a grain-like texture. The corrosion front has increased to an apparent height of up to $25 \mu \mathrm{m}$. Singular circular shapes occur especially in B2. A3-C3 After $72 \mathrm{~h}$ the majority of the corrosion products reside on the outer perimeters of the samples and reaches apparent heights of up to $140 \mu \mathrm{m}$. In the middle of B3 pits are revealed. One of these pits have been investigated with Raman

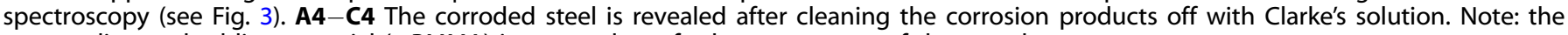
surrounding embedding material (=PMMA) is cropped out for better contrast of the sample

into rates demonstrates the corrosive power of up to $2.5 \mathrm{~mm}$ year $^{-1}$. Areas of low corrosion rates correspond to areas of high oxide/hydroxide heights. This resembles the typical anodic -cathodic electrochemical kinetics, which are discussed later on.

\section{Rate maps and rate spectra}

After $72 \mathrm{~h}$ of experimental runtime all corrosion products were cleaned off with Clarke's solution, revealing the material damage through the corrosion process. Large areas of the surface have been dissolved causing a surface normal retreat (Table 1) ranging from 0 to $25 \mu \mathrm{m}$. This measured surface normal retreat is converted into corrosion rates of up to $3.5 \mathrm{~mm} \mathrm{year}^{-1}$ (e.g., see ref. ${ }^{17}$ ). The outer edges of the samples, where the majority of the corrosion products were found (Fig. 2, A3-C3), have nearly no surface normal retreat $\left(\sim 2 \mu \mathrm{m}\left(0.25 \mathrm{~mm}\right.\right.$ year $\left.\left.^{-1}\right)\right)$. Whereas majority of the region in the middle of the samples have around $9 \mu \mathrm{m}$ retreat $\left(=1.2 \mathrm{~mm}\right.$ year $\left.^{-1}\right)$. The characteristic appearance of the rate maps is seen more clearly in the histogram of the rate distribution, known as rate spectrum. The spectra of all three samples show two major peaks (Fig. 4, (4)). Therefore, the deconvolution of the rate spectrum results in two Gaussian curves which quantify two characteristic corrosion domains, one at relatively low and one at relatively high corrosion rates. The centers of the Gaussian curves and their half width at half maximum (HWHM) are listed in Table 1 . These values quantify the rate behavior seen in the rate maps.
Sample A (Fig. 4, (1)) has a region with high corrosion rates in the upper area. The cross-section of this region (Fig. 4, (5)) exposes three pits forming the rectangular shape with a dominant deep pit reaching a surface normal retreat of $29 \mu \mathrm{m}\left(=3.94 \mathrm{~mm}_{\text {year }}{ }^{-1}\right)$.

Likewise, sample $B$ exhibits pits, yet these are rather dispersed throughout the surface. The pits can be linked to the circular corrosion product shapes found in Fig. 2 (B3). Their corrosion reaches surface normal retreat values of up to $21 \mu \mathrm{m}(=2.94 \mathrm{~mm}$ year $\left.{ }^{-1}\right)$. Sample $C$ shows no pits and has a rather uniform corrosion behavior with a retreat of $14 \mu \mathrm{m} \quad\left(=2 \mathrm{~mm}_{\text {year }}{ }^{-1}\right)$ covering a large part of the sample surface. This results in a more flattened rate distribution of domain 2 (Fig. 4, (4)) leading to a high HWHM of $0.52 \mathrm{~mm}$ year $^{-1}$ (Table 1).

The mean rate of $0.79 \mathrm{~mm}$ year $^{-1}$ is found between the two domains.

In addition, the pitting impact can be determined by the ratio of pitting corrosion rate to total corrosion rate across the entire sample (Table 1). The highest pitting impact has sample $A$ with $2.44 \%$. The amount of steel material loss can be quantified via the cleaned topography and can then be calculated into material loss per area showing an average of $11.01 \mathrm{E}-3 \mathrm{~mm}^{3} \mathrm{~mm}^{-2}$ (see Table 1 for more information).

Corrosion product topography maps and height distribution Figure 5 (1)-(3) display the maps of the absolute height distribution. These data determine the distance between the 
Table 1. Quantification of steel corrosion

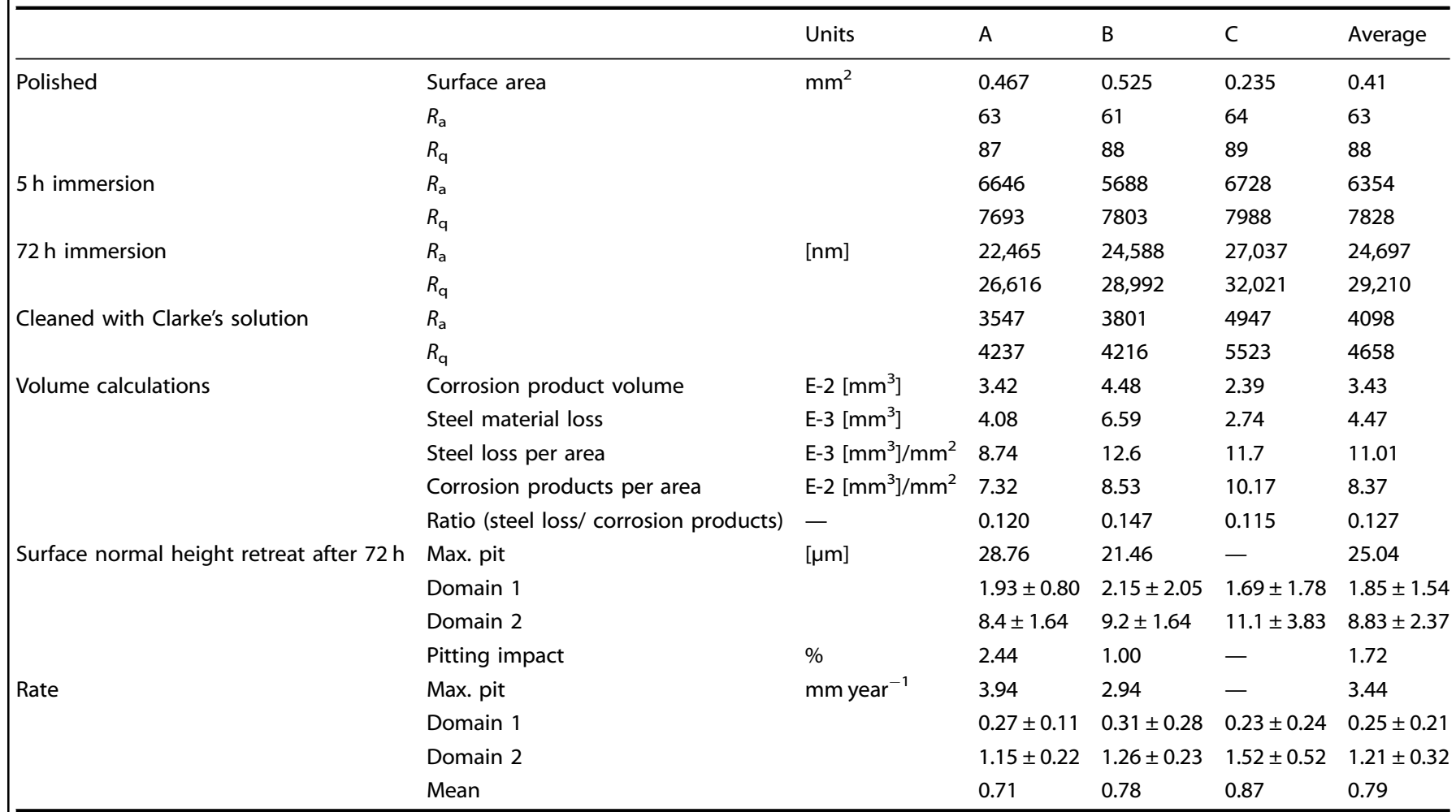

Overview of the data obtained through the topographic measurements (VSI). Surface area refers to the scanned area of the steel surface. Surface roughness values $\mathrm{Ra}$ (roughness average) and Rq (root- mean-square) are provided to describe the surface alteration. The surface normal retreat and rate behavior is quantified by the peak center and half width at half maximum $( \pm)$ of the deconvolved Gaussian curves. Sample $C$ had no pitting corrosion

corroded steel surface and the corrosion products after $72 \mathrm{~h}$ of immersion in $\mathrm{NaCl}$ (see Methods) and allow the quantification of the volume. Sample $C$ has a volume of $10.17 \mathrm{E}-2 \mathrm{~mm}^{3} \mathrm{~mm}^{-2}$ while the average is only $8.37 \mathrm{E}-2 \mathrm{~mm}^{3} \mathrm{~mm}^{-2}$.

Similar to the corrosion rate distribution, the absolute heights can be visualized in a corrosion product histogram. This shows a different shape than the rate spectra and resembles a rather continuous decrease as the absolute height increases. The deconvolution by Gaussian curves delivers no proper quantification; further research is here necessary. In correlation to the observed uniform corrosion in sample $\mathrm{C}$ the absolute height distribution shows a high frequency between 60 and $100 \mu \mathrm{m}$, following an exponential decrease till $140 \mu \mathrm{m}$. Whereas the other two samples A and B reach a maximum at 100-120 $\mu$ m (Fig. 5, (4))).

Strong metal dissolution tends to occur at locations of low absolute heights. This demonstrates the spatial electrochemical behavior of steel corrosion.

\section{DISCUSSION}

The lifetime of a material is difficult to predict as lab experiments cannot consider all environmental factors, yet even relatively simple experiments are of a complex nature as seen here. The quantification of these processes results in a heterogeneous distribution of values. Taking a simple mean may give a broad overview, yet often fails to describe important details and may even present a rate result that does not exist (see Fig. 4). For example, the mean surface roughness parameters taken from the entire steel surface illustrate the alteration of steel corrosion by increasing its surface roughness from initially $R_{\mathrm{q}}=64 \mathrm{~nm}$ to $R_{\mathrm{q}}=$ $4947 \mathrm{~nm}$ (for sample $C$ cleaned with Clarke's solution, Table 1).
While samples A and B show a similar increase in surface roughness, the deep pits of up to $28.76 \mu \mathrm{m}$ (Table 1) are not described by these mean roughness values. A convergence analysis could assess representable roughness values. ${ }^{18}$

Mean values require a normal distribution; however, this normal distribution is often not realized. Our alternative concept considers the entire rate spectrum, i.e., the spatial distribution of all rates measured on a representative section of the corroding steel surface. The principle of our approach and measurement techniques are demonstrated in this paper by conducting a $72 \mathrm{~h}$ long experiment. For real corrosion systems the run duration may be significantly longer depending on system parameters such as temperature, $\mathrm{pH}$, steel material and solution composition. ${ }^{19}$

Due to the rate distribution a mean value may overlook the damaging effect of locally constrained high corrosion rates. Consider a pipeline wall thickness of $17.5 \mathrm{~mm},{ }^{20}$ using the maximum pitting rate of $3.94 \mathrm{~mm}$ year $^{-1}$ observed here, a pipeline failure could occur already after $\sim 4-5$ years. The mean rate ( $0.79 \mathrm{~mm}$ year $^{-1}$ ) would suggest a lifetime of $\sim 21$ years.

In this study a concept derived from mineralogical applications $^{10,11}$ that assesses the rate distribution via rate maps and rate spectra is presented, thus, providing an extensive description of the complex corrosion behavior. The rate distribution ranges from two major rate contributing domains $0.25 \pm 0.21$ and $1.21 \pm$ $0.32 \mathrm{~mm}$ year $^{-1}$ (Fig. 4, (4)) to a maximum pitting rate of $3.44 \mathrm{~mm}$ year $^{-1}$ (Table 1). This provides a more comprehensive description than a single mean corrosion rate of $0.79 \mathrm{~mm}_{\text {year }}{ }^{-1}$ (Table 1).

The rates are derived from a short-term exposure time of $72 \mathrm{~h}$. Therefore, the calculated rates mainly demonstrate the principles of this new concept. In any case, they are relevant for the initial corrosion behavior of the system. In order to determine the actual long-term behavior of a material, longer immersion times may be 

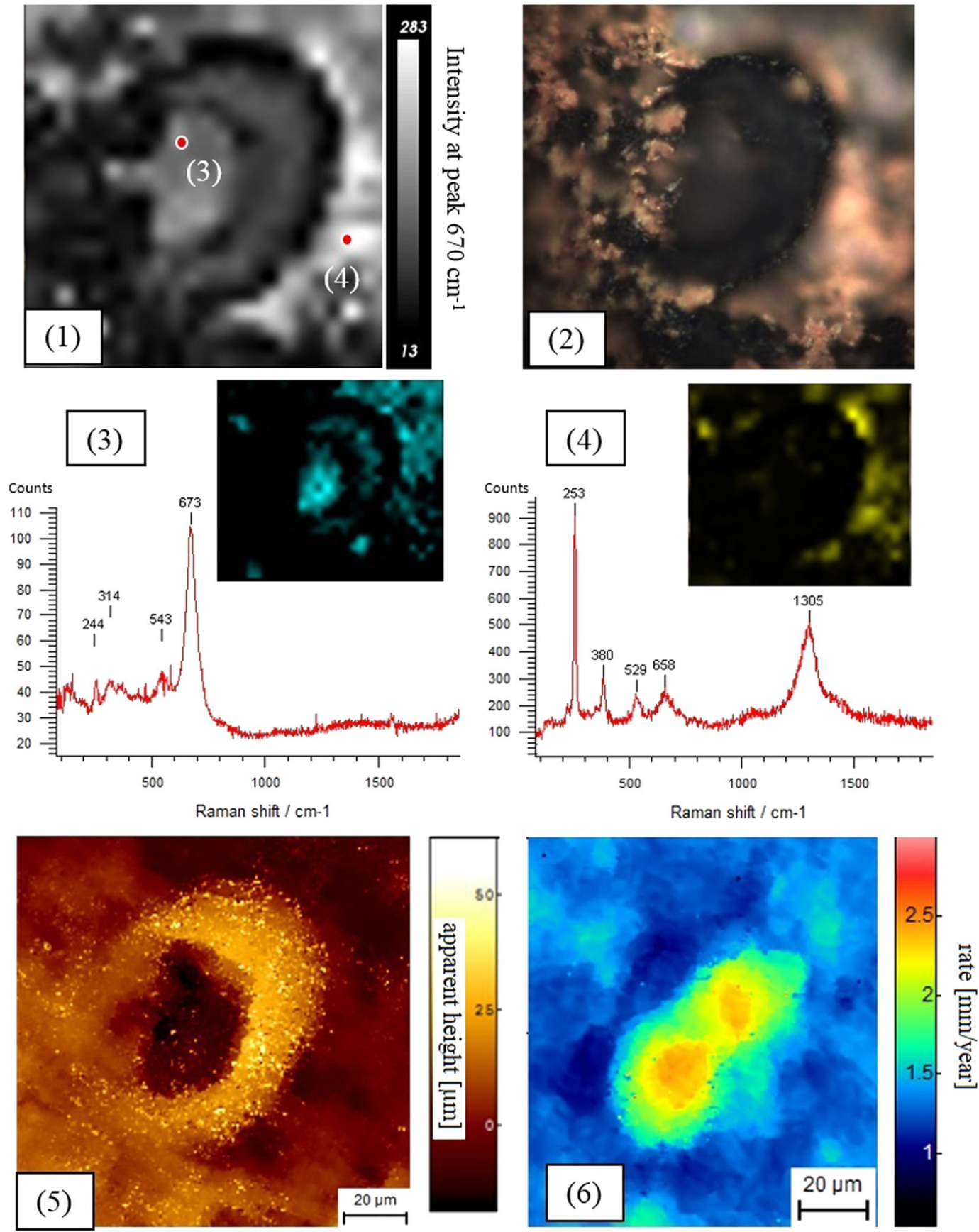

Fig. 3 Raman-coupled vertical scanning interferometer measurements: Detailed examination of the corrosion products after $72 \mathrm{~h}$ immersion. (1) The Raman map is generated by the intensity at peak $670 \mathrm{~cm}^{-1}$. The areas of lower intensity relate to a mixture of iron oxides and hydroxides. (2) Light microscope image at $\times 50$ magnification. (3) Raman spectra of Magnetite occurs mainly in the middle of the pit, as indicated by the blue Raman map. (4) Raman spectra of Fe-hydroxide, found especially around the pit (yellow Raman map). (5) Topography map shows the apparent height after $72 \mathrm{~h}$ immersion. (6) After cleaning the corrosion products off with Clarke's solution and subsequent data processing the rate map reveals two pits

advised because corrosion kinetics may be subject to change as a function of time. ${ }^{9,19,21,22}$ Pit stability is hereby an important aspect since pitting does not occur at a linear constant rate ${ }^{2}$ and tends to have a maximum lifetime. ${ }^{23}$ Corrosion product formation is also a dynamic process. In accordance with other studies ${ }^{24}$ after $5 \mathrm{~h}$ immersion a significant corrosion product layer is found on the pits (Fig. 2, (A2-C2)). After $72 \mathrm{~h}$ the majority has dissolved at these locations (Fig. 2, (A3-C3)).

The corrosion products on the surface influence the steel dissolution underneath. ${ }^{25,26}$ The RC-VSI is capable of delivering insight into the relationship between metal dissolution and corrosion product formation. The findings represented here are in agreement with other studies ${ }^{27}$ as Fe-oxides, e.g., magnetite, are found in close vicinity to the dissolving pit center, whereas Fehydroxides, e.g., lepidocrocite are found only in a distance from the pits (e.g., Fig. 3).

Pits can take on irregular localized behavior ${ }^{5,6,28}$ where e.g. micro pits join up to form macro pits, ${ }^{29}$ as seen in sample A (Fig. 4, $(1),(5))$. The occurrence of high reactive sites in close proximity present a potential weakness in the material, which can lead to 

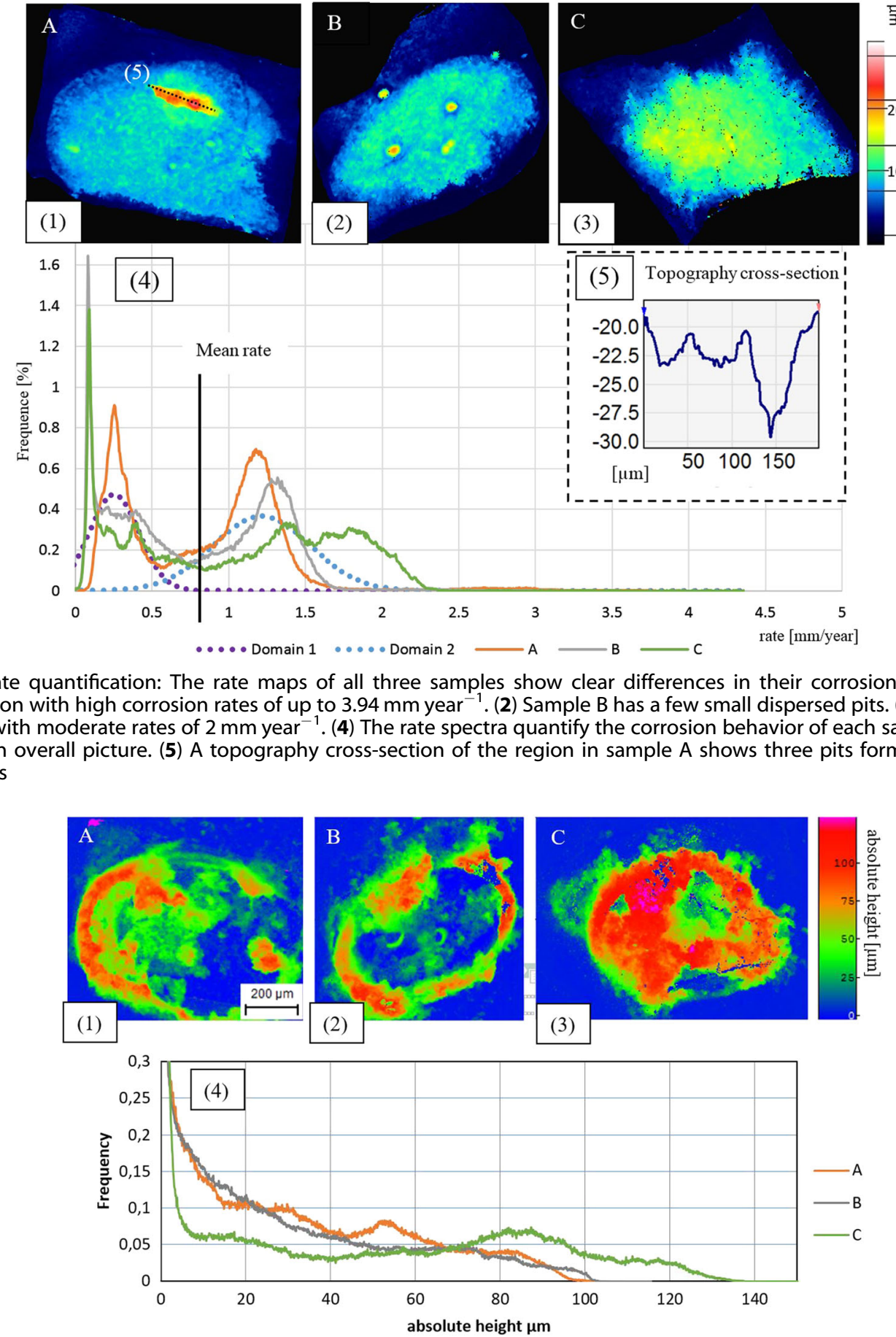

Fig. 5 Absolute heights of the corrosion products: (1)-(3) The absolute heights of the corrosion products after $72 \mathrm{~h}$ of immersion. (4) The histogram of all three samples represent the distribution of absolute height values and show a relative continuous decrease. Sample $\mathrm{C}$ has a high frequency of corrosion products at $70-100 \mu \mathrm{m}$ height

degradation faster than predicted by the overall mean rate. This is particularly true in the perspective of real-world applications, where pressure, mechanical forces, ${ }^{30}$ and microbial corrosion ${ }^{31,32}$ can have an additional negative effect. The direct combination of rate maps with Raman spectroscopy maps is a powerful tool in future applications giving the possibility of precisely quantifying such heterogeneously distributed surface reactions.

The RC-VSI measurements and data processing provides a wealth of information about the corrosion process, yet limitations exist. The orthogonal white light beam of the VSI allows only surface normal pit depth measurements. If the pit grows under the surface, as seen in crevice corrosion, this method would not be able to detect the underlying dissolution. Further evaluation with e.g. $\mu$-CT would be necessary to determine the true pit shape.

The corrosion product volume method presented here measures only the surface topography. Therefore, it is not possible to evaluate the density of the corrosion products and possible voids or air bubbles that may exist beneath the surface. This might 


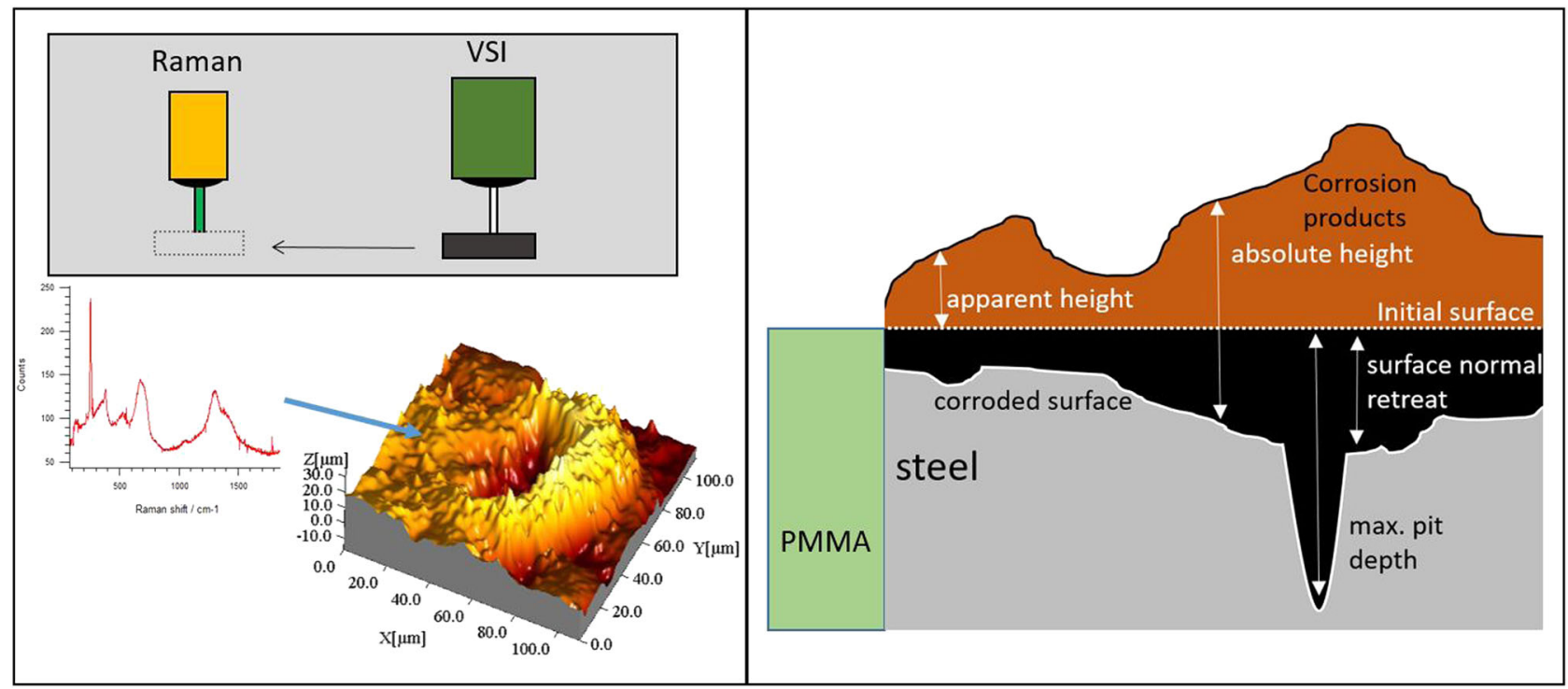

Fig. 6 Data acquisition and processing: (1) Schematic view of the data acquisition setup. The sample stage can move between the Raman and the VSI and allows fast and precise measurements. (2) Data processing overview. Schematic cross-section of a surface that has undergone corrosion. The embedding material serves as a reference height (PMMA = polymethylmethacrylate). The absolute height is determined by subtracting the height of the corroded steel surface from the height of the corrosion product surface. The surface normal retreat is calculated by subtracting the corroded surface from the initial surface. The apparent height is the distance between the initial surface/PMMA and the corrosion product surface

explain the low ratio of steel material lost to corrosion product volume determined here (Table 1).

When cleaning off the corrosion products with Clarke's solution, due to the $\mathrm{HCl}$, small amounts of steel are dissolved. ${ }^{33,34}$ This can lead to a slight increase in the rate provided in domain 1. Using the presented method additional research is necessary to assess the effect of Clarke's solution on the corrosion rates.

The introduction of RC-VSI enables the quantification of corrosion rates and analyses of corrosion products. Specifically, the method provides spatially resolved steel corrosion maps (rate maps), corrosion product maps, and Raman spectroscopy maps. The combination of these data generates insight in reaction mechanism(s) and kinetics in this way. Here, the surface of the corroding steel shows an inhomogeneous distribution of the corrosion processes. Therefore, simple mean values, rate constants, derived for the bulk material are not an adequate representation of the spectrum of corrosion rates. Instead, a concept is proposed and tested that is based on the measuring of the corroding surface topographies and the subsequent generation of rate maps leading finally to the desired rate spectra. This method provides a comprehensive quantification of reaction kinetics, i.e., corrosion behavior. In contrast to the conventional rate constant, rate spectra represent a new tool for an overall material characteristic quantification: the classification of the frequencies of corrosion rate occurrence with the potential of analyzing the individual rate modes and their contributions to the overall rate.

\section{METHODS}

Three API X70 steel samples were embedded into one sample holder with polymethylmethacrylate (PMMA) and polished with a $3 \mu \mathrm{m}$ diamond suspension. The ex situ immersion experiments were performed at room temperature $\left(21^{\circ} \mathrm{C}\right)$ for $72 \mathrm{~h}$, in a $1 \mathrm{~L} \mathrm{NaCl}(3.5 \mathrm{wt} . \%)$ solution with $\mathrm{pH}$ of 6 . After immersion, the corrosion products were cleaned off with Clarke's solution $\left(100 \mathrm{ml} \mathrm{HCl}, 2 \mathrm{~g} \mathrm{Sb}_{2} \mathrm{O}_{3}\right.$ and $\left.5 \mathrm{~g} \mathrm{SnCl}_{2}\right)$, uncovering the corroded steel surface. To minimize further corrosion, the immersion time in the Clarke's solution was only $3 \mathrm{~min}$ and done in an ultra-sonic bath ${ }^{34}$.

In order to evaluate the corrosion behavior as a function of time, two measurement periods of 5 and $72 \mathrm{~h}$ were taken. The corrosion products were cleaned off after $72 \mathrm{~h}$ with Clarke's solution and then measured with the VSI. All topography measurements were performed by a Bruker GT vertical scanning interferometer (VSI) in white light mode with a vertical resolution up to the Ångstrom level. This method has been described in detail. ${ }^{10,17,35,36}$ The measurements were performed with a $\times 5$ objective, with a measurement area of $x=952.4 \mu \mathrm{m}, y=714.3 \mu \mathrm{m}$ and a lateral sampling of $0.744 \mu \mathrm{m}$. The measurements were stitched together (also known as tiling). The initial roughness (before corrosion) of the samples was calculated using SPIP classic parameters (subtraction from mean). The roughness average $R_{\mathrm{a}}$ and root mean square $R_{\mathrm{q}}$ represent the mean surface roughness of the entire steel surface.

The interferometer is coupled to a Raman spectrometer from Renishaw and is equipped with a $532 \mathrm{~nm}$ laser (Fig. 6, (1)). The coordinates of the VSI measurements are calculated into the Raman coordinates thereby linking the spatially resolved height distribution directly to the chemical information of the corrosion products. The laser power for the measurements was $1.2 \mathrm{~mW}$. The Renishaw database was used for identification of the spectra; further confirmation was achieved by the RRUFF database and other studies. ${ }^{27}$ The topography data were evaluated with SPIP (Imagemet) software. Surface normal retreat is calculated by subtracting the topography maps of the initial and corroded steel surface (Fig. 6, (2)) thereby generating a material flux map. Hereby, the PMMA is set to a constant height of zero and serves as a reference height and is also used as a baseline for the maximum pitting depth measurements (Fig. 6, (2)). The alignment of the individual measurements was done by characteristic surface features found on the PMMA. The subtraction of different topographies delivers various quantification (Fig. 6 (2)). The material flux maps, that show the surface normal retreat, can then be calculated into rate maps by taking the reaction time into consideration. These rate maps visualize the rate distribution ${ }^{10,11}$ across the surface. Furthermore, the frequency of surface normal retreat rate occurrences can be shown in a histogram, i.e., in a frequency spectrum. Rate domains and mechanisms are distinguished by deconvoluting the histogram into different normal type curves. This final histogram is termed as rate spectrum. ${ }^{11}$

The absolute corrosion product volume can be obtained adding up all the absolute height values. In the same procedure the surface normal retreat values yield the volume of steel material lost.

\section{DATA AVAILABILITY}

The raw data presented in this study are available from the PANGAEA database. Processed data can also be obtained from the corresponding author upon reasonable request. 


\section{ACKNOWLEDGEMENTS}

Hereby we would like to thank Ricarda D. Rohlfs, Elisabete Trindade Pedrosa, Malte Bahro, Inna Kurganskaya, Till Bollermann, and Mohammad Khalid Bin Mahbub for fruitful discussions and advice. A special thanks to our technician Marcos Toro assisting the measurements. We gratefully acknowledge support from sponsors that have funded our work: The Deutsche Forschungsgemeinschaft (DFG) INST 144/378-1, and INST 144/388-1

\section{AUTHOR CONTRIBUTIONS}

J.H. and A.L. designed the research; J.H. performed the research; J.H. analyzed the data; and J.H. and A.L. wrote the paper.

\section{ADDITIONAL INFORMATION}

Competing interests: The authors declare no competing interests.

Publisher's note: Springer Nature remains neutral with regard to jurisdictional claims in published maps and institutional affiliations.

\section{REFERENCES}

1. Koch, G. H., Brongers, M. P., Thompson, N. G., Virmani, Y. P., \& Payer, J. H. . Corrosion cost and preventive strategies in the United States. NACE. No. FHWARD-01-156, (2002).

2. Frankel, G. S. Pitting corrosion of metals. J. Electrochem. Soc. 145, 2186 (1998).

3. Leblanc, P. \& Frankel, G. S. A study of corrosion and pitting initiation of AA2024T3 using atomic force microscopy. J. Electrochem. Soc. 149, B239-B247 (2002).

4. Lorenz, W. J. \& Mansfeld, F. Determination of corrosion rates by electrochemical DC and AC methods. Corros. Sci. 21, 647-672 (1981).

5. Burstein, G. T., Liu, C., Souto, R. M. \& Vines, S. P. Origins of pitting corrosion. Corros. Eng., Sci. Technol. 39, 25-30 (2004).

6. Turnbull, A. Review of modelling of pit propagation kinetics. Br. Corros. J. 28, 297-308 (1993).

7. Dwivedi, D., Lepková, K. \& Becker, T. Carbon steel corrosion: a review of key surface properties and characterization methods. RSC Adv. 7, 4580-4610 (2017).

8. Machnikova, E., Arvidson, R., Fischer, C., Luttge, A. \& Whitmire, K. Insights into the kinetics of acid corrosion reactions from direct analysis of surface morphology. Geochim. Cosmochim. Acta 72, A580 (2008).

9. Melchers, R. E. Progress in developing realistic corrosion models. Struct. Infrastruct. Eng. 14, 843-853 (2018).

10. Fischer, C. \& Luttge, A. Beyond the conventional understanding of water-rock reactivity. Earth Planet. Sci. Lett. 457, 100-105 (2017).

11. Lüttge, A., Arvidson, R. S. \& Fischer, C. Fundamental controls of dissolution rate spectra: comparisons of model and experimental results. Procedia Earth Planet. Sci. 7, 537-540 (2013).

12. Fischer, C., Arvidson, R. S. \& Lüttge, A. How predictable are dissolution rates of crystalline material? Geochim. Cosmochim. Acta 98, 177-185 (2012).

13. Clover, D., Kinsella, B., Pejcic, B. \& Marco, Rde The influence of microstructure on the corrosion rate of various carbon steels. J. Appl. Electrochem. 35, 139-149 (2005).

14. Guo, P. et al. Direct observation of pitting corrosion evolutions on carbon steel surfaces at the nano-to-micro-scales. Sci. Rep. 8, 7990 (2018).

15. Contreras, E. Q. et al. Optical measurement of uniform and localized corrosion of C1018, SS 410, and Inconel 825 alloys using white light interferometry. Corros. Sci. 87, 383-391 (2014).

16. Holme, B. \& Lunder, O. Characterisation of pitting corrosion by white light interferometry. Corros. Sci. 49, 391-401 (2007).

17. Luttge, A., Bolton, E. W. \& Lasaga, A. C. An interferometric study of the dissolution kinetics of anorthite; the role of reactive surface area. Am. J. Sci. 299, 652-678 (1999).

18. Fischer, C. \& Lüttge, A. Converged surface roughness parameters-a new tool to quantify rock surface morphology and reactivity alteration. Am. J. Sci. 307, 955-973 (2007).
19. Gin, S., Dillmann, P. \& Birbilis, N. Material Degradation Foreseen in the Very Long Term: The Case of Glasses and Ferrous Metals. npj Materials Degradation 1, 10 (2017).

20. Gräf, M., Schröder, J., Schwimm, V. \& Hulka, K. Production of large diameter pipes grade X70 with high toughness using acicular ferrite microstructures. In International Conference on Application and Evaluation of High Grade Linepipes in Hostile Enviroments, Yokohama, Japan (2002).

21. La Fuente, Dde, Díaz, I., Simancas, J., Chico, B. \& Morcillo, M. Long-term atmospheric corrosion of mild steel. Corros. Sci. 53, 604-617 (2011).

22. Melchers, R. E. Extreme value statistics and long-term marine pitting corrosion of steel. Probabilistic Eng. Mech. 23, 482-488 (2008).

23. Tian, W., Du, N., Li, S., Chen, S. \& Wu, Q. Metastable pitting corrosion of 304 stainless steel in 3.5\% NaCl solution. Corros. Sci. 85, 372-379 (2014).

24. Wang, Y., Cheng, G. \& Li, Y. Observation of the pitting corrosion and uniform corrosion for $\mathrm{X} 80$ steel in $3.5 \mathrm{wt} . \% \mathrm{NaCl}$ solutions using in-situ and 3-D measuring microscope. Corros. Sci. 111, 508-517 (2016).

25. Refait, P., Grolleau, A.-M., Jeannin, M., François, E. \& Sabot, R. Localized corrosion of carbon steel in marine media: galvanic coupling and heterogeneity of the corrosion product layer. Corros. Sci. 111, 583-595 (2016).

26. Ramya, S., Nanda Gopala Krishna, D. \& Mudali, U. K. In-situ Raman and X-ray photoelectron spectroscopic studies on the pitting corrosion of modified $9 \mathrm{Cr}$ 1 Mo steel in neutral chloride solution. Appl. Surf. Sci. 428, 1106-1118 (2018).

27. Li, S. \& Hihara, L. H. In situ Raman spectroscopic study of $\mathrm{NaCl}$ particle-induced marine atmospheric corrosion of carbon steel. J. Electrochem. Soc. 159, C147 (2012).

28. Bhandari, J., Khan, F., Abbassi, R., Garaniya, V. \& Ojeda, R. Modelling of pitting corrosion in marine and offshore steel structures-a technical review. J. Loss Prev. Process Ind. 37, 39-62 (2015).

29. Jeffrey, R. \& Melchers, R. E. The changing topography of corroding mild steel surfaces in seawater. Corros. Sci. 49, 2270-2288 (2007).

30. Melchers, R. E. The effect of corrosion on the structural reliability of steel offshore structures. Corros. Sci. 47, 2391-2410 (2005).

31. Wade, S., Javed, M. A., Palombo, E., Mcarthur, S. \& Stoddart, P. On the need for more realistic experimental conditions in laboratory-based microbiologically influenced corrosion testing. Int. Biodeterioration Biodegrad. 121, 97-106 (2017).

32. Videla, H. A. \& Herrera, L. K. Microbiologically influenced corrosion: looking to the future. Int. Microbiol. 8.3, 169 (2005).

33. Chaves, I. A., Jeffrey, R. \& Melchers, R. E. The effect of cleaning procedures on corrosion coupon surface topography. Annual Conference of the Australasian Corrosion Association 2014: Corrosion and Prevention 2014, Darwin, Australia (2014).

34. Wade, S. \& Lizama, Y. Clarke's solution cleaning used for corrosion product removal: effects on carbon steel substrate. Annual Conference of the Australasian Corrosion Association 2015: Corrosion and Prevention 2015, Adelaide, Australia (2015).

35. Harasaki, A., Schmit, J. \& Wyant, C. Improved vertical-scanning interferometry. Appl. Opt. 39, 2107-2115 (2000).

36. Arvidson, R. S. et al. Lateral resolution enhancement of vertical scanning interferometry by sub-pixel sampling. Microsc. Microanal. 20, 90-98 (2014).

Open Access This article is licensed under a Creative Commons Attribution 4.0 International License, which permits use, sharing, adaptation, distribution and reproduction in any medium or format, as long as you give appropriate credit to the original author(s) and the source, provide a link to the Creative Commons license, and indicate if changes were made. The images or other third party material in this article are included in the article's Creative Commons license, unless indicated otherwise in a credit line to the material. If material is not included in the article's Creative Commons license and your intended use is not permitted by statutory regulation or exceeds the permitted use, you will need to obtain permission directly from the copyright holder. To view a copy of this license, visit http://creativecommons. org/licenses/by/4.0/.

(c) The Author(s) 2018 